\title{
Evaluation of factor VIII polymorphic short tandem repeat markers in linkage analysis for carrier diagnosis of hemophilia A
}

\author{
SABINA SHRESTHA, SUFANG DONG, ZUHUA LI, ZHULIANG HUANG and FANG ZHENG \\ Center for Gene Diagnosis, Zhongnan Hospital of Wuhan University, Wuhan, Hubei 430071, P.R. China
}

Received March 17, 2016; Accepted June 10, 2016

DOI: 10.3892/br.2016.712

\begin{abstract}
Hemophilia A (HA) is the most common inherited $\mathrm{X}$-linked recessive bleeding disorder caused by heterogeneous mutations in the factor VIII gene (FVIII). Diagnosis of the carrier is critical for preventing the birth of children affected by this coagulation disorder, which ultimately facilitates its management. Due to the heterogeneous nature of mutations, the large inversions and the complexity of the FVIII gene, direct recognition of the disease-associated mutation in HA is complex. Indirect linkage analysis using highly informative heterozygous polymorphic markers is an alternative method for determining the co-segregation of the mutant gene within a family for carrier detection of HA. The aim of the present study was to perform carrier diagnosis in a family with HA. Rapid multifluorescent polymerase chain reaction (PCR) was performed with six extragenic short tandem repeats (STRs), DXS1073, DXS15, DXS8091, DXS1227, DXS991, DXS993 and one intragenic marker, STR22 for linkage analysis in the HA family. All the STR markers employed in the present study were informative for linkages of pathogenic and healthy haplotypes among family members, particularly STR22, DXS1073 and DXS15. The STR marker, STR22, is within the FVIII gene while the DXS1073 and DXS15 markers are very close to the FVIII gene, where the chances of recombination are comparatively low, and provided the most accurate interpretation analysis, indicating that the proband's sister may have been the HA carrier. Rapid multifluorescent PCR using STR markers and linkage analysis was identified to be a simple method for performing HA carrier diagnosis.
\end{abstract}

Correspondence to: Professor Fang Zheng, Center for Gene Diagnosis, Zhongnan Hospital of Wuhan University, 169 Donghu Road, Wuhan, Hubei 430071, P.R. China

E-mail: zhengfang@whu.edu.cn

Key words: hemophilia A, carrier diagnosis, linkage analysis, short tandem repeats, multifluorescent polymerase chain reaction

\section{Introduction}

Hemophilia A (HA; OMIM: 306700) is a disorder of the coagulation system that is experienced worldwide (1). HA, the result of reduced factor VIII (FVIII) activity (2), is an X-linked recessive bleeding disorder characterized by defects in the FVIII gene, which codes for the FVIII protein. Membrane-bound FVIII performs a critical function in blood coagulation as the pro-cofactor to the serine-protease, factor IXa (FIXa) in the FVIIIa-FIXa complex assembled on the activated platelet membrane (3). HA is rare (4), although it is the most common inherited bleeding disorder (5), and has a high treatment cost (6). The incidence of HA is $\sim 1$ in 10,000 live male births (7). Typically, affected patient experience prolonged bleeding caused by lack or reduced residual activity of the coagulant FVIII (FVIII:C). The severity of the disease is defined based on the quantity of the residual FVIII:C level (8). As recessive X-linked disease, the HA phenotype is manifested in hemizygous males whereas heterozygous females (carrier) are usually asymptomatic, showing normal or intermediate FVIII activity (FVIII:C) levels (9). As a carrier, there is $50 \%$ probability of transmitting the abnormal allele to the child (10). HA is rare in females (11); however, there are various potential genetic mechanisms leading to HA in certain females, as follows: i) homozygous mutations as consequence of consanguineous marriage (12); ii) heterozygous FVIII mutation combined with skewed inactivation of X chromosome (13); and iii) compound heterozygous mutations (11). FVIII, a plasma glycoprotein coded by a 186-kb gene with 26 exons is located at the Xq28 position (chrX: 154,835,795-155,022,753; University of California, Santa Cruz genome browser, GRCh38/hg38). Since the publication of sequence FVIII gene by Gitschier et al (14) at Genetech in 1984, numerous mutations causing HA have been identified. The most common is the inversion of intron 22 , which occurs in $40-50 \%$ of patients with severe HA (15), whereas the inversion of intron 1 is present in just $1-5 \%$ of patients (16).

Currently, it is proposed that the diagnosis of HA should be extended to genetic testing, to establish the causative mutation $(17,18)$. Determination of the mutation responsible for HA is important for various reasons, including: i) Enabling a preliminary assessment of the risk of FVIII inhibitor development; and ii) identifying a definitive diagnosis of HA carrier status (17). 
Carrier diagnosis is critical for preventing the birth of children affected by coagulation disorders. There are two genetic methods for the analysis of genes involved in HA, direct and indirect. Direct sequence analysis of the FVIII gene is a gold standard for genetic diagnosis of HA (19). However, in 2-5\% of patients with severe HA a causative mutation is occasionally not identified in FVIII gene (20). Direct sequencing of the FVIII gene for carrier detection in developing countries is limited by the large size and mutational heterogeneity of the gene. This limitation is overcome by indirect analysis of polymorphisms linked to the FVIII gene, rendering carrier detection economically practicable (19).

Linkage analysis requires other affected family members with informative polymorphic markers to track the affected allele (21). Short tandem repeats (STRs), restriction fragment length polymorphism (RFLP), and variable number tandem repeats (VNTR) are used as polymorphic markers. Linkage analysis is a common indirect method for detection of female carriers in families with HA (22). In the present study, a combination of intragenic and extragenic STR markers was used in linkage analysis for carrier diagnosis in a Chinese HA family.

\section{Materials and methods}

Subjects. The present study was conducted in two generations of a HA family; the mother was a carrier, the son was the proband, the father was healthy and the daughter was the suspected carrier. Written informed consent was obtained from each member of the family. Venous blood samples $(\sim 10 \mathrm{ml})$ were drawn from each member and collected in EDTA vacutainers at Zhongnan Hospital, Wuhan University (Wuhan, China). Genomic DNA was extracted from white blood cells according to the conventional phenol-chloroform method using an ultracentrifuge (Hema Medical Instrument Co., Ltd., Guangdong, China).

Polymorphic markers and primers. The STR markers selected to assess their efficacy as genetic diagnosis markers in the present study were STR22, an intragenic marker, and six extragenic STR polymorphic markers, DXS1073, DXS15, DXS8091, DXS1227, DXS991 and DXS993. These markers were selected based on the GenBank database (http://www.ncbi.nlm.nih.gov/genbank/), Genome Database (The University of California, Santa Cruz genome browser) and Ensembl (http://www.ensembl.org/index.html). The DXS15 and STR22 primers were synthesized and labeled with fluorescent dye, 5'6-FAM (Sangong Company Shanghai, China) and are presented in Table I. The DXS1073, DXS8091, DXS1227, DXS991 and DXS993 primers were from an ABI Linkage Mapping Set v2.5 MD10 (Applied Biosystems; Thermo Fisher Scientific, Inc., Waltham, MA, USA).

Polymerase chain reaction (PCR) amplification and capillary electrophoresis. PCR was conducted in a total volume of $25 \mu \mathrm{l}$ containing $1 \mu \mathrm{l}$ genomic DNA (40-50 ng/ $\mu \mathrm{l}), 1 \mu \mathrm{l}$ primer pair mix (10 $\mu \mathrm{M}$ each primer), $0.5 \mu \mathrm{l} \mathrm{dNTPs}(10 \mathrm{mmol} / \mathrm{l})$, $2.5 \mu \mathrm{MgCl}_{2}(25 \mathrm{mM})$ and 10X PCR Buffer, (Thermo Fisher Scientific, Inc., Waltham, MA, USA) $1 \mu \mathrm{l}$ Taq polymerase

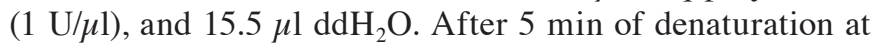

$95^{\circ} \mathrm{C}, 35$ cycles of the following were performed: Denaturation at $94^{\circ} \mathrm{C}$ for $30 \mathrm{sec}$; annealing at $55^{\circ} \mathrm{C}$ for DXS1073, DXS8091, DXS1227, DXS991, and DXS993, at $60^{\circ} \mathrm{C}$ for STR22 or at $58^{\circ} \mathrm{C}$ for DXS15, for $30 \mathrm{sec}$; extension at $72^{\circ} \mathrm{C}$ for $30 \mathrm{sec}$; and final extension at $72^{\circ} \mathrm{C}$ for $5 \mathrm{~min}$. Each of the PCR products was diluted 10 -fold using $\mathrm{ddH}_{2} \mathrm{O}$. Subsequently, GeneScan ${ }^{\mathrm{TM}}$ 500 LIZ $^{\circledR}$ Size Standards (Thermo Fisher Scientific, Inc.) and formamide (Thermo Fisher Scientific, Inc.) were combined at a ratio of 1:3, and $3 \mu \mathrm{l}$ diluted PCR products was mixed with $9 \mu 1$ GeneScan $^{\mathrm{TM}} 500 \mathrm{LIZ}^{\circledR}$ Size Standards/formamide. Following denaturation at $95^{\circ} \mathrm{C}$ for $5 \mathrm{~min}$ and rapid cooling on ice, the mixture was electrophoresed and separated by capillary electrophoresis on an ABI 3130 Genetic Analyzer (Thermo Fisher Scientific, Inc.) and results were analyzed using GeneMapper ID software v3.2 (Applied Biosystems; Thermo Fisher Scientific, Inc.) according to a previous study (23).

\section{Results}

Six extragenic markers and one intragenic marker were employed for carrier diagnosis of the daughter who was thought to be an HA carrier. Electrophoretogram results obtained from capillary electrophoresis are presented in Fig. 1 and demonstrate that all of the STR markers employed in the present study were informative for linkage analysis of pathogenic and healthy haplotypes among the HA family members (Table II). For the seven STR markers (Fig. 2), the haplotype in the son (III-1), the proband, and that of the mother (II-2), who was a carrier, are identical. The sister (III-2) of the proband carried the same haplotype as the proband, which came from her mother, an obligate carrier. STR22, an intragenic marker, and DXS15 and DXS1073 are closer to the FVIII gene with low chances of recombination, indicating that these three markers possess more diagnostic characteristic features, which increased the accuracy of the result. Thus, the use of these markers (STR22, DXS15 and DXS1073) assisted with identifying that the proband's sister may be a carrier of HA.

\section{Discussion}

HA is the most common bleeding disorder with $\mathrm{X}$-linked recessive inheritance caused by a wide variety of mutations in the FVIII gene located in chromosome Xq28. FVIII is the only gene known to be associated with HA (7). Given the hemizygous nature of X-linked disorders, males are primarily affected, while females are commomly heterozygous for the gene mutation and are typically referred as carriers (24). The female carriers are usually asymptomatic with bleeding events occurring in only $\sim 10 \%$ of cases (25). There is a $50 \%$ chance that a carrier mother will transmit the defective X-linked gene to the male or female child. All female offspring born to a hemophilic father are obligate carriers. To identify the females at risk of being a carrier, it is important to understand the heriditary of the disorder. Although sporadic cases result from de novo mutations (20), carrier detection and prenatal diagnosis is critical for reducing the number of births of children with hemophilia in developing countries, where patients with this particular coagulation disorder rarely survive beyond childhood (25). 
Table I. Primer sequences of STR22 and DXS15 polymorphic markers with fluorescent dyes.

\begin{tabular}{llr}
\hline Primer names & Forward primers & Reverse primers \\
\hline STR22 & 5'-GTACTGGGAATGCACAGCCTA-3' & 5'-(FAM)CCAGACATGTCAAGGTGTCAA-3' \\
DXS15 & 5'-(5'6-FAM) AGCACATGGTATAATGAACCTCCACG-3' & 5'-CAGTGTGAGTAGCATGCTAGCATTTG-3' \\
\hline
\end{tabular}

Table II. STR linkage result from the HA family.

\begin{tabular}{|c|c|c|c|c|c|}
\hline STR marker & Father & Mother & Daughter & Son & Loci \\
\hline STR22 & 207.26 & $205.32 / 205.32$ & $205.33 / 207.24$ & 205.33 & \\
\hline DXS1073 & 310.02 & $307.98 / 310.11$ & $307.98 / 310.11$ & 307.94 & $X: 154,835,788-155,026,940$ \\
\hline DXS15 & 153.02 & $153 / 157.18$ & $152.94 / 152.94$ & 153 & $X: 153,366,650-153,366,809$ \\
\hline DXS8091 & 84.4 & $84.50 / 82.49$ & $84.41 / 84.41$ & 84.43 & $X: 148,521,335-148,521,437$ \\
\hline DXS1227 & 79.49 & $79.52 / 81.54$ & $79.52 / 79.52$ & 79.53 & X: $141,714,259-141,714,432$ \\
\hline DXS991 & 333.77 & $331.78 / 333.80$ & $331.82 / 333.80$ & 331.87 & $X: 55,492,619-55,492,898$ \\
\hline DXS993 & 207.45 & $268.58 / 270.51$ & $268.58 / 270.51$ & 268.56 & $X: 41,288,430-41,288,735$ \\
\hline
\end{tabular}

Haplotype segregation in two generations of an HA family representing the healthy and pathogenic risk haplotypes, and intragenic and extragenic STR marker loci in the X chromosome of the factor VIII gene (Ensembl database; http://www.ensembl.org). STR, short tandem repeat; HA, hemophilia A.

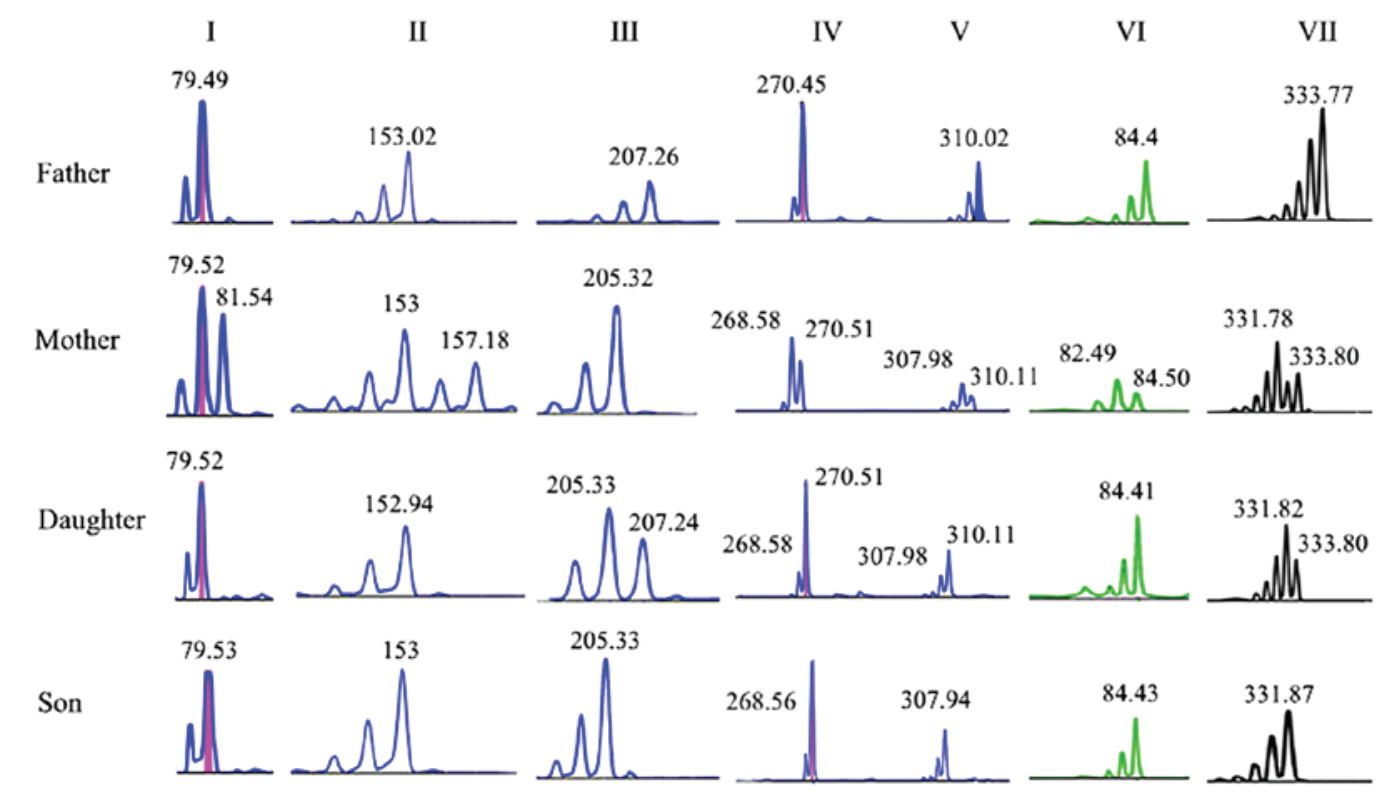

Figure 1. Electrophoretogram of seven short tandem repeat markers in the family with hemophilia A. I, DXS1227; II, DXS15; III, STR22; IV, DXS993; V, DXS1073; VI, DXS8091; VII, DXS991. Father, healthy; mother, carrier; daughter, suspected carrier; son, proband.

Molecular analysis techniques, including the direct and indirect analysis of the FVIII gene sequence have increased the detection rate of HA carriers (22). Genetic counseling, carrier testing, and prenatal diagnosis of hemophilia have become an integrated aspect of the comprehensive care for hemophilia during the past three decades.

Direct sequence analysis of the FVIII gene is a gold standard for genetic diagnosis of HA (19). However, due to heterogenous nature of mutations, the large size of inversions and the complexity of FVIII gene, direct recognition of the disease-associated mutation is complicated. Linkage analysis is an auxillary strategy to direct mutation analysis for genetic counseling of HA (26). Indirect linkage analysis using highly informative polymorphic markers is the method of choice for carrier detection of HA in developing countries, as direct DNA or mRNA sequence analysis is significantly more costly and difficult when compared with indirect gene tracking (19). Polymorphic markers are slight DNA sequence variations usually present in the non-coding regions of a gene in the population. The sequences are stable and inherited according 


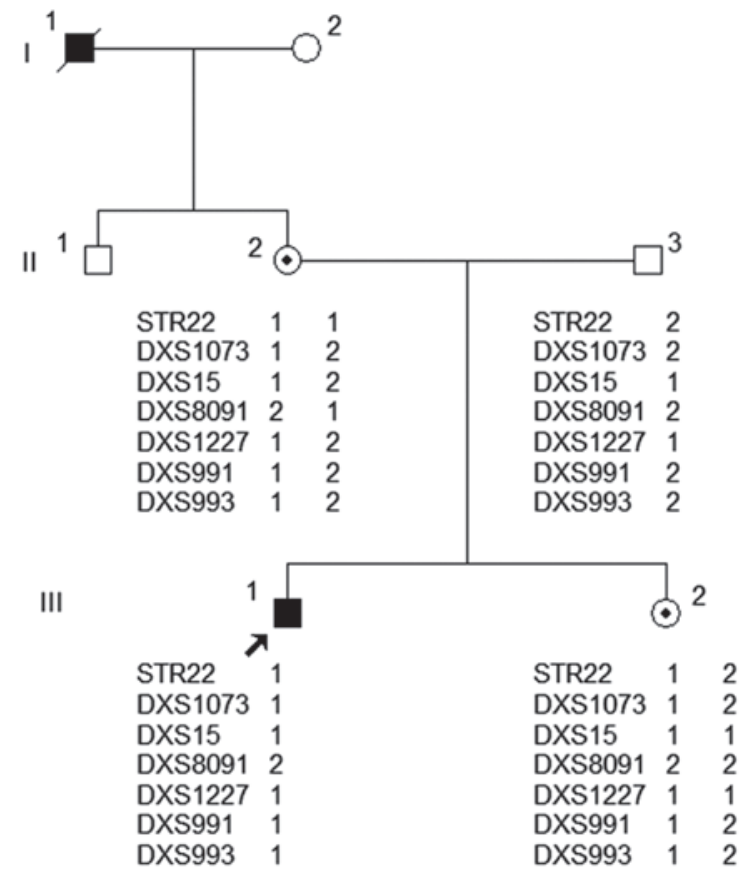

Figure 2. Pedigree and haplotype analysis of the microsatellite panel in an extended family with hemophilia A. Square, male; circle, female; filled square with diagonal line, proband; dotted circle, carrier. The number beside each marker denotes the quantity of microsatellite repeats. STR, short tandem repeat.

to Mendel's laws. However linkage analysis has certain limitations, for example this technique requires entire families and cannot be conducted on isolated individuals. Furthermore, it presumes that the stated relationships are correct. The frequency of recombination is a major concern. Recombination events between FVIII and the extragenic site occur in $\leq 5 \%$ of meiosis (leads to misdiagnosis), although these have not been observed between hemophilic and intragenic sites (27). Thus, the probability of meiotic recombination should be considered while using linked markers for HA diagnosis.

Following observation of normal FVIII (67.7\%) and FIX (90.9\%) activity in the proband's sister, the aim of the present study was to use STR markers to perform linkage analysis to establish whether the sister of the proband was a carrier of HA. For this investigation a combination of one intragenic STR marker and six extragenic markers was used. The intragenic marker, STR22 (a dinucleotide repeats sequence in intron 22) and DXS1073, DXS15, DXS8091, DXS1227, DXS991 and DXS993 extragenic markers are linked to the FVIII gene. Following analysis of the haplotypes obtained from an electrophoretogram, the STR haplotypes were able to effectively isolate the healthy and pathogenic haplotypes among the family members, particularly STR22, an intragenic marker, and DXS15 and DXS1073, which are closer to the FVIII gene; thus providing sufficient evidence to establish the carrier status.

As a consequence of genetic variation among different populations, a high degree of genetic difference has been identified between various ethnic groups, such as Chinese, Asian Indian, Turkish, Russian, Japanese and Caucasian. Therefore, there is a requirement to establish the specific markers linked to the FVIII gene in each population (22). The heterozygosity rate $(\mathrm{HR})$ of each marker in the control population requires investigation to identify suitable markers for genetic diagnosis in the given study population in order to perform efficient tracking of the chromosome carrying the mutant gene.

The efficacies of various polymorphic markers linked to the FVIII gene have been studied in different ethnic groups and found to differ significantly. In the study by Li et al (28). HRs of 88 and $62 \%$ were observed for DXS15 and DXS1073 markers, respectively in a Chinese population. DXS15 with HR 77.4\% was observed in a Hungarian population (29). In the study done by Liang et al (30) a HR of $43.6 \%$ for STR22 was observed in a Chinese population. A higher HR is indicative of a higher efficiency of DNA diagnosis in HA (31).

Additional polymorphic markers were used in numerous studies; in a study of a Chinese population by Sun et al (32) HRs of 26.3 and $15.8 \%$ for $B c l$ I (polymorphic site in intron 18) and HindIII (polymorphic site in intron 19), respectively were observed; whereas, in a Turkish population, HRs were 47 and 35\% for BclI and HinIII, respectively (22). It is possible that these two polymorphism markers are less informative in a Chinese population. Similarly, Sun et al (32), used STR markers in intron 1 and observed an HR of $27.7 \%$ and the marker in intron 24 was not helpful with diagnosing any of the families in that study. Highly informative extragenous VNTR St14 (DXS52) (heterozygosity $\leq 90 \%$ ) burdened with a high risk of recombination (3-5\%) and is used in exceptional cases only where other VNTR markers were not enough for molecular diagnosis (25). The risk of recombination of the external markers limits the use of RFLP in tracking the defective allele. Additional informative intragenic markers, such as STR increase the accuracy of analysis (33). Furthermore, Dai et al (34) observed the HR of $21.57 \%$ for G6PD and $35.29 \%$ for DXS1108 in Chinese population, which was consistent with previous report (35).

Thus, accurate carrier detection of HA and effective early prenatal diagnosis represent the most effective forms of disease control. Linkage analysis, with a combination of intragenic and extragenic markers, is considered to be optimal for avoiding misdiagnosis due to recombination and hence results in an accurate diagnosis. In conclusion, multiflourescent PCR employing STR22, DXS15 and DXS1073 polymorphic markers, during linkage analysis, which was conducted in the present study was identified to be convenient and efficient, and may be performed in clinical laboratories for carrier detection in Chinese HA families. Despite certain limitations in the linkage analysis method for indirect carrier detection, it is a widely used approach and provides an alternative strategy when direct mutation is not feasible for genetic counseling of HA.

\section{References}

1. Mansouritorghabeh $\mathrm{H}$ : Clinical and laboratory approaches to hemophilia a. Iran J Med Sci 40: 194-205, 2015.

2. Paroskie A, Oso O, Almassi B, DeBaun MR and Sidonio RF Jr: Both hemophilia health care providers and hemophilia a carriers report that carriers have excessive bleeding. J Pediatr Hematol Oncol 36: e224-e230, 2014.

3. Dalm D, Galaz-Montoya JG, Miller JL, Grushin K, Villalobos A, Koyfman AY, Schmid MF and Stoilova-McPhie S: Dimeric organization of blood coagulation factor VIII bound to lipid nanotubes. Sci Rep 5: 11212, 2015. 
4. Karaman K, Akbayram S, Garipardıç M and Öner AF: Diagnostic evaluation of our patients with hemophilia A: 17-year experience. Turk Pediatri Ars 50: 96-101, 2015.

5. Shastry SP, Kaul R, Baroudi K and Umar D: Hemophilia A Dental considerations and management. J Int Soc Prev Community Dent 4 (Suppl 3): S147-S152, 2014.

6. Zhou ZY, Koerper MA, Johnson KA, Riske B, Baker JR, Ullman M, Curtis RG, Poon JL, Lou M and Nichol MB: Burden of illness: Direct and indirect costs among persons with hemophilia A in the United States. J Med Econ 18: 457-465, 2015.

7. Lheriteau E, Davidoff AM and Nathwani AC: Haemophilia gene therapy: Progress and challenges. Blood Rev 29: 321-328, 2015.

8. Pezeshkpoor B, Pavlova A, Oldenburg J and El-Maarri O: F8 genetic analysis strategies when standard approaches fail. Hamostaseologie 34: 167-173, 2014.

9. Radic CP, Rossetti LC, Abelleyro MM, Tetzlaff T, Candela M, Neme D, Sciuccati G, Bonduel M, Medina-Acosta E, Larripa IB, et al: Phenotype-genotype correlations in hemophilia A carriers are consistent with the binary role of the phase between F8 and X-chromosome inactivation. J Thromb Haemost 13: 530-539, 2015.

10. Roualdes O, Nougier C, Fretigny M, Talagrand E, Durand B, Negrier $C$ and Vinciguerra C: Usefulness of an in vitro cellular expression model for haemophilia A carrier diagnosis: Illustration with five novel mutations in the F8 gene in women with isolated factor VIII:C deficiency. Haemophilia 21: e202-209, 2015.

11. Qiao SK, Ren HY, Ren JH and Guo XN: Compound heterozygous hemophilia $\mathrm{A}$ in a female patient and the identification of a novel missense mutation, p.Met1093Ile. Mol Med Rep 9: 466-470, 2014.

12. Gurjar V and Gurjar M: Consanguineous marital union resulting in a progeny of whistling-face syndrome and hemophilia: A case report. J Int Oral Health 7: 78-80, 2015.

13. Zheng J, Ma W, Xie B,Zhu M, Zhang C,Li J, Wang Y, Wang M and Jin Y: Severe female hemophilia A patient caused by a nonsense mutation (p.Gln1686X) of F8 gene combined with skewed $\mathrm{X}$-chromosome inactivation. Blood Coagul Fibrinolysis 26: 977-978, 2015.

14. Gitschier J, Wood WI, Goralka TM, Wion KL, Chen EY, Eaton DH, Vehar GA, Capon DJ and Lawn RM: Characterization of the human factor VIII gene. Nature 312: 326-330, 1984.

15. Kumar P, Husain N, Soni P, Faridi NJ and Goel SK: New protocol for detection of intron 22 inversion mutation from cases with hemophilia A. Clin Appl Thromb Hemost 21: 255-259, 2015.

16. Odnoczko E, Stefańska-Windyga E, Baran B, Górska-Kosicka M, Sowińska I, Bykowska K and Windyga J: Detection of inversion mutations (INV22 and INV1) in F8 gene using IS-PCR method in Polish patients with severe hemophilia A. Acta Haematol Pol 46: 372-377, 2015.

17. Edyta Odnoczko JW: Genetic testing in hemophilia A diagnostic. Hematologia 5: 193-202, 2014.

18. Sawecka J, Skulimowska J, Windyga J and Koscielak J: Inversion of intron 1 of factor VIII gene in patients with severe hemophilia A. Acta Haematologica Polonica 37: 61-65, 2006.

19. Bugvi SM, Imran M, Mahmood S, Hafeez R, Fatima W and Sohail S: Screening of intron 1 inversion and three intragenic factor VIII gene polymorphisms in Pakistani hemophilia A families. Blood Coagul Fibrinolysis 23: 132-137, 2012.
20. Jayandharan GR, Srivastava A and Srivastava A: Role of molecular genetics in hemophilia: From diagnosis to therapy. Semin Thromb Hemost 38: 64-78, 2012.

21. Kessler L, Adams R, Mighion L, Walther S and Ganguly A: Prenatal diagnosis in haemophilia A: Experience of the genetic diagnostic laboratory. Haemophilia 20: e384-391, 2014.

22. Moharrami T, Derakhshan SM, Pourfeizi AA and Khaniani MS: Detection of hemophilia a carriers in Azeri Turkish population of Iran: usefulness of HindIII and BclI markers. Clin Appl Thromb Hemost 21: 755-759, 2015

23. Rong Y, Gao J, Jiang X and Zheng F: Multiplex PCR for 17 Y-chromosome Specific Short Tandem Repeats (STR) to enhance the reliability of fetal sex determination in maternal plasma. Int J Mol Sci 13: 5972-5981, 2012.

24. Sidonio RF, Mili FD, Li T, Miller CH, Hooper WC, DeBaun MR and Soucie M; Hemophilia Treatment Centers Network: Females with FVIII and FIX deficiency have reduced joint range of motion. Am J Hematol 89: 831-836, 2014

25. Saxena $R$ and Ranjan R: Prenatal Diagnosis of Hemophilia A and B. J Mol Biol \& Mol Imaging 1: 1-6, 2014

26. Ding QL, Lu YL, Dai J, Xi XD, Wang XF and Wang HL: Characterisation and validation of a novel panel of the six short tandem repeats for genetic counselling in Chinese haemophilia A pedigrees. Haemophilia 18: 621-625, 2012.

27. Klopp N, Oldenburg J, Uen C, Schneppenheim R and Graw J: 11 hemophilia A patients without mutations in the factor VIII encoding gene. Thromb Haemost 88: 357-360, 2002.

28. Li SY, Ma XY, Zhang HM, Wang XM and Li Q: A multifluorescent STR-PCR for prenatal gene diagnosis of hemophilia A carriers. J Pract Med 27: 2050, 2011.

29. Bors A, Andrikovics H, Illés Z, Jáger R, Kardos M, Marosi A, Nemes L and Tordai A: Carrier and prenatal diagnostic strategy and newly identified mutations in Hungarian haemophilia A and B families. Blood Coagul Fibrinolysis 26: 161-166, 2015.

30. Liang Y, Zhao Y, Yan M, Fan XP, Xiao B and Liu JZ: Prenatal diagnosis of haemophilia A in China. Prenat Diagn 29: 664-667, 2009.

31. de Carvalho FM, de Vargas Wolfgramm E, Paneto GG, de Paula Careta F, Spagnol Perrone AM, de Paula F and Louro ID: Analysis of factor VIII polymorphic markers as a means for carrier detection in Brazilian families with haemophilia A. Haemophilia 13: 409-412, 2007.

32. Sun P, Ma L, Diao G, Li CQ and Lin FZ: Application of indirect linkage analysis and direct genotyping to hemophilia A carrier detection in Sichuan, China. Genet Mol Res 14: 8229-8235, 2015.

33. Rabbani B, Rezaeian A, Khanahmad H, Bagheri R, Kamali E and Zeinali S: Analysing two dinucleotide repeats of FVIII gene in Iranian population. Haemophilia 13: 740-744, 2007.

34. Dai J, Lu Y, Ding Q, Wang H, Xi X and Wang X: The status of carrier and prenatal diagnosis of haemophilia in China. Haemophilia 18: 235-240, 2012.

35. Fang Y, Wang XF, Dai J and Wang HL: A rapid multifluorescent polymerase chain reaction for genetic counselling in Chinese haemophilia A families. Haemophilia 12: 62-67, 2006. 